\title{
Nasal-type extranodal natural killer/T-cell lymphomas: a clinicopathologic and genotypic study of 42 cases in Singapore
}

\author{
Siok Bian Ng${ }^{1}$, Kin Wai Lai ${ }^{1}$, Sivakumar Murugaya ${ }^{1}$, Khai Mun Lee ${ }^{2}$, Susan Li Er Loong ${ }^{3}$, \\ Stephanie Fook-Chong ${ }^{4}$, Miriam Tao ${ }^{5}$ and Ivy Sng ${ }^{1}$ \\ ${ }^{1}$ Department of Pathology, Singapore General Hospital, Singapore; ${ }^{2}$ Department of Radiation Oncology, \\ National University Hospital, Singapore, ${ }^{3}$ Department of Therapeutic Radiology, National Cancer Centre, \\ Singapore; ${ }^{4}$ Department of Clinical Research, Singapore General Hospital, Singapore and ${ }^{5}$ Department of \\ Medical Oncology, National Cancer Centre, Singapore
}

\begin{abstract}
We studied the clinicopathologic features of 42 cases of nasal-type extranodal natural killer (NK)/T-cell lymphoma in Singapore and compared our findings with other series reported in the Asian and Western populations. A panel of immunohistochemical stains, which included CD2, CD3, CD4, CD8, CD56, T-cell intracellular Antigen-1 and granzyme B, and in situ hybridization for Epstein-Barr virus encoded RNA (EBER) were performed. Polymerase chain reaction for T-cell receptor-gamma gene rearrangement using both gel and capillary electrophoresis were evaluated to determine the proportion of tumors which are of true T-cell lineage. We also studied the functional status of the overexpressed p53 protein in these lymphomas by correlating p53 expression with its downstream target protein, p21. In all, 31 out of 42 cases presented in the upper aerodigestive tract. The other sites of involvement included gastrointestinal tract, skin, soft tissue, testis, liver, spleen, bone marrow and brain. The tumors displayed characteristic morphologic features. In situ hybridization for EBER was detected in $\mathbf{4 1}$ out of 42 cases $(\mathbf{9 7 . 6 \% )}$. The only significant adverse prognostic factor identified was an International Prognostic Index of two or more. A significantly higher proportion of the tumors (27\%), compared to previous studies, demonstrated monoclonal T-cell receptor-gamma gene rearrangement. There was, however, no difference in survival or clinicopathologic features between the true NK-cell tumors and their T-cell counterparts. Overexpression of p53 was present in $40 \%$ of the cases, but no significant difference in survival rate was detected in patients with p53 overexpression and there was no association between p53 overexpression with large cell morphology, and advanced stage of disease. These findings suggest that molecular aberrations other than those of the p53 pathway may be operative in the pathogenesis of this malignancy.

Modern Pathology (2004) 17, 1097-1107, advance online publication, 11 June 2004; doi:10.1038/modpathol.3800157
\end{abstract}

Keywords: capillary electrophoresis; Epstein-Bar virus; natural killer/T-cell lymphoma; p53 and p21; T-cell receptor-gamma gene rearrangement

Natural killer (NK)-cell malignancies encompass several distinct clinicopathologic entities. The prototype, extranodal nasal-type NK-cell lymphomas, has been well described in the last few years. ${ }^{1-3}$ These lymphomas are postulated to originate from activated NK cells. ${ }^{4}$ However, rare cases with identical clinical, histologic and immunohistochemical features may be of true T-cell derivation. ${ }^{2,5-9}$

Correspondence: Dr SB Ng, FRCPA, Department of Pathology, Singapore General Hospital, Outram Road, Singapore 169608, Singapore.

E-mail: gptnsb@sgh.com.sg

Received 6 January 2004; revised 29 March 2004; accepted 30 March 2004; published online 11 June 2004
This small proportion of tumors appears to be derived from a unique subset of cytotoxic $\mathrm{T}$ cells, known as NK-like or $\mathrm{NK} 1^{+} \mathrm{T}$ cell, and shows monoclonally rearranged T-cell receptor genes. ${ }^{10-12}$ Hence, the term NK/T-cell lymphoma (NK/TCL) is preferred. ${ }^{4,5}$ To date, about 200 cases of NK/TCLs have been documented in the literature, mostly from Chinese, Japanese, Korean and South American populations. $^{3,4}$ In contrast, this tumor is rarely encountered in the West, where only about 30 cases have been reported so far. ${ }^{3}$ This racial predisposition may be partly related to the prevalence of Epstein-Barr virus infection in Oriental patients. ${ }^{3}$ NK/TCL generally occurs in the adult male and often presents as a destructive midline lesion in the 
nasal region. Identical tumors may also be encountered in other extranodal sites, including skin and subcutaneous soft tissue, gastrointestinal tract, and testis. ${ }^{2,4}$ These neoplasms often pose difficulties in diagnosis and classification as a result of their rarity, lack of well-established etiologic and genetic data, and very importantly, heterogeneity in their clinical, morphologic and immunophenotypic attributes. Although frequently implicated in the pathogenesis of many human cancers, the role of p53 as a prognostic and predictive factor and its involvement in the pathogenesis of nasal-type NK/TCL is unclear. A few studies have noted a high incidence of p53 overexpression and/or mutations, ${ }^{12,13}$ and some investigators also found an association between p53 mutation with large cell morphology and advanced disease. ${ }^{14}$

In this study, we describe the clinicopathologic and genotypic findings of 42 cases of nasal-type NK/ TCL in Singapore, which is a multiracial society populated predominantly by Asians, and compared our findings with those of other series reported in the Eastern ${ }^{8,15-18}$ and Western populations. ${ }^{19-22} \mathrm{We}$ analyzed the clonality of T-cell receptor- $\gamma$ gene using both traditional agarose gel electrophoresis and highly sensitive capillary electrophoresis in order to determine the proportion of NK/TCL that are of true NK derivation and compared these tumors with their T-cell counterparts with regards to their histologic features and clinical behavior. To investigate the prognostic importance and role of p53 in the pathogenesis of NK/TCL, we studied the immunohistochemical expression of p53 and evaluated the functional status of the overexpressed protein by correlating with the expression of its downstream target protein, p21.

\section{Materials and methods}

\section{Case Selection}

Patients with a diagnosis of extranodal Angiocentric $\mathrm{T}$ cell and NK/TCLs were identified from the archives of the Department of Pathology, Singapore General Hospital, from the period of 1992 to 2002. The pathologic diagnosis and classification of nasal and non-nasal NK/TCLs were based on the criteria described by Jaffe et al. ${ }^{6}$ Cases were classified as NK/TCL when they showed (i) histologic features of nasal and nasal-type malignant lymphoma, (ii) expression of T-cell marker (CD2 and/or cCD3), CD56 and cytotoxic molecules, (iii) expression of Epstein-Barr virus encoded RNA (EBER) by in situ hybridization, and (iv) absence of B-cell phenotype with CD20. For cases which were negative for EBER, T-cell receptor- $\gamma$ gene must be in the germline configuration for them to be categorized as NK/ TCL. The cases which were negative for CD56 but positive for both cytotoxic markers and EBER were also included.
In all, 71 cases of extranodal NK/TCL and NK-like TCLs were selected for review. Four cases of extranodal peripheral TCLs not otherwise specified, one case of angioimmunoblastic TCL, eight cases of subcutaneous panniculitic-like TCL, one case of cutaneous anaplastic TCL, five cases of NK-like TCLs with similar histologic features but lacked EBER expression and displayed clonal T-cell receptor- $\gamma$ gene rearrangement, and 10 cases with no additional tissue available for immunohistochemical or molecular workup were excluded. The remaining 42 cases formed the basis of this study.

\section{Clinical Findings}

The clinical information was obtained from the hospital's medical records. Information regarding the survival status was available from the Singapore Cancer Registry and the Registry of Births and Deaths for 38 cases. Four cases were lost to followup. The patients were staged clinically according to the Ann Arbor system, ${ }^{16}$ except for cases with skin tumors, which were staged according to the TNM staging of cutaneous TCL. ${ }^{23}$ Survival was analyzed as a function of time from histologic diagnosis to the last date of follow-up in December 2002, using Kaplan-Meier product limit method. The upper aerodigestive tract included nasal, paranasal sinuses, nasopharynx, pharynx, oral cavity, hypopharynx and tonsillar regions. Patients with tumors manifesting at a different site, 6 months after the initial diagnosis, were considered to have dissemination of the disease. The association of various clinicopathologic parameters with survival time was assessed and these included age, sex, stage, International Prognostic Index (IPI), various treatment modalities, site of tumors, size of tumor cells, EBER expression, and cell lineage. The statistical analysis was undertaken using SPSS software for Windows, version 10 . Two-sided $P$-value less than 0.05 was considered statistically significant.

\section{Histologic and Immunophenotypic Studies}

The morphologic features of the cases studied were evaluated on $4-\mu \mathrm{m}$ tissue sections cut from formalinfixed, paraffin-embedded tissue blocks and stained with hematoxylin and eosin. The tumors were assessed independently by two of the authors (SBN and IS) for the presence of necrosis, accompanying inflammatory infiltrate, and angiocentricity. The cases were also stratified, according to the size of the tumor cells, into (i) predominantly small, (ii) medium and small, or predominantly medium, (iii) large and medium, or predominantly large, and (iv) mixed category with a spectrum of small to large tumor cells.

For immunohistochemical analysis, 5- $\mu \mathrm{m}$ tissue sections from formalin-fixed, paraffin-embedded blocks of tissues were stained with antibodies to 
CD20 (L26, Ventana, neat), CD2 (2CO2, Neomarker, 1:100), CD3 (polyclonal, Ventana, neat), CD8 (C8/ 144b, Dako, 1:100), CD4 (4B12, Novocastra, 1:500), CD56 (123C3.D5, Neomarker, 1:150), T-cell Intracellular Antigen-1 (TIA-1, ImmunoTech, 1:250), Granzyme B (GrB-7, Dako, 1:100), p53 (DO-7, Dako, 1:1500), and p21 ${ }^{\mathrm{WAF} 1}$ (SX118, Dako, 1:50), using the streptavidin-biotin complex technique with microwave and pressure cooker antigen retrieval methods. Appropriate positive controls were used for all immunohistochemical stains. Staining for cCD3, CD4, CD8, CD56, TIA-1 and granzyme B was considered positive when $10 \%$ or more of the abnormal lymphoid cells showed positive immunoreactivity. Normal colonic mucosa and reactive tonsils were used as positive controls for p21. ${ }^{24-26}$ Immunohistochemical reactivity for p21 was scored as follows: $0,<5 \%$ of tumor cell nuclei positive; $1+, 5-<10 \%$ of tumor cell nuclei positive; $2+, 10-<20 \%$ of tumor cell nuclei positive; $3+$, $20-<30 \%$ of tumor cell nuclei positive; $4+$, $30 \%$ or more of tumor cell nuclei positive. Immunohistochemical expression of p53 was scored as follows: $0,<10 \%$ of tumor cell nuclei positive; $1+, 10-<25 \%$ of tumor cell nuclei positive; $2+$, $25-<50 \%$ of tumor cell nuclei positive; $3+, 50-$ $<75 \%$ of tumor cell nuclei positive; $4+, 75 \%$ or more of tumor cell nuclei positive.

\section{In Situ Hybridization}

In situ hybridization for EBER was performed using Dako Peptide Nucleic Acid in situ hybridization detection kit. Paraffin sections $(4 \mu \mathrm{m})$ were deparaffinized with xylene, treated with proteinase $\mathrm{K}$, and hybridized with fluorescein-conjugated peptide nucleic acid probe. After stringent washing, alkaline phosphatase-conjugated rabbit $F(a b$ ') antifluorescein isothiocyanate conjugated was added followed by enzyme substrate bromo-chloroindoyl phosphate/nitroblue tetrazolium for detection. A blue or brown-blue color within the nucleus was considered a positive reaction. A known EpsteinBarr virus-positive tumor was used as a positive control. For cases with negative reaction to EBER, a positive control directed against glyceraldehyde 3-phosphate dehydrogenase was performed to assess the quality of the RNA.

\section{Polymerase Chain Reaction (PCR) with Gel and Capillary Electrophoresis}

For PCR amplification of the T-cell receptor- $\gamma$ locus, sections were cut from formalin-fixed, paraffinembedded tissues, deparaffinized with xylene and ethanol. After overnight digestion with proteinase $\mathrm{K}$, DNA was extracted using the QIAamp mini kit (Qiagen, GmbH, Germany). The concentration of DNA extracted was measured by a spectrophotometer. A multiplex PCR reaction was performed as previously described, ${ }^{27}$ using three consensus primers complimentary to all the three known joining region genes (Jp, J1/2 and Jp1/2) and five concensus primers complimentary to the different families of variable region genes (V) (Table 1). A $50 \mu$ l PCR reaction mixture was prepared using PCR reaction buffer (Invitrogen), $3 \mathrm{mM}$ of magnesium chloride (Invitrogen), $100 \mu \mathrm{M}$ of each dNTPs (Promega), $0.6 \mu \mathrm{M}$ of each primers, and $1.25 \mathrm{U}$ of platinum Taq polymerase (Invitrogen). Samples were run in duplicate, together with positive and negative controls. A total of 40 cycles of PCR was performed in a Hybaid Omnigene thermal cycler. The PCR products were electrophoresed in $3.5 \%$ NuSieve ${ }^{\circledR}$ GTG $^{\mathbb{R}}$ agarose gel and visualized with ethidium bromide. The expected molecular weight of the appropriate PCR products range in size from 160 to 220 base pairs. PCR using primers to $\beta$-globin/ house-keeping gene was also performed to assess the integrity of the DNA. The presence of a clonal T-cell population was determined by the identification of 1 or 2 reproducible bands. Nonreproducible and smear patterns were interpreted as negative (polyclonal).

Capillary electrophoresis was performed as described previously, ${ }^{27}$ using the ABI PRISM 310 Genetic Analyzer (Applied Biosystems, CA, USA). PCR products $(2 \mu \mathrm{l})$ were mixed with $10 \mu \mathrm{l}$ of deionized formamide (Sigma) and $0.5 \mu \mathrm{l}$ of GENESCAN-350 ${ }^{\mathrm{TM}}$ ROX DNA size standard (Applied biosystems, CA, USA). Injection was set at $5 \mathrm{~s}, 15 \mathrm{kV}$ and running at $15 \mathrm{kV}, 60^{\circ} \mathrm{C}$. Each joining region gene primer was tagged with a fluorescent dye and represented by the following colors: Jp with 6-Fam: blue, J1/2 with NED: black, Jp1/2 with VIC: green, and the Rox size standard: red. The presence of a clonal T-cell population was determined by the presence of 1 or 2 reproducible peaks which had to

Table 1 Primers for T-cell receptor- $\gamma$ gene rearrangement ${ }^{29}$

\begin{tabular}{llll}
\hline Primer & J $\gamma$-labeled PCR & Sequence $5^{\prime}-3^{\prime}$ & Source \\
\hline $\mathrm{J} \gamma \mathrm{P}$ & FAM & AAGCTTTGTTCCGGGACCAAATAC & Applied Biosystems, CA, USA \\
$\mathrm{J} \gamma 1 / \mathrm{J} \gamma 2$ & NED & TACCTGTGACAACAAGTGTTGTTC & Applied Biosystems, CA, USA \\
$\mathrm{J} \gamma \mathrm{P} 1 / \mathrm{J} \gamma \mathrm{P} 2$ & $\mathrm{VIC}$ & GAAGTACTATGAGC(T/C)TAGTCCCT & Applied Biosystems, CA, USA \\
$\mathrm{V} \gamma 2$ & & ACTCCAGGGTTGTGTTGGAATCA & Research Biolabs, Singapore \\
$\mathrm{V} \gamma 3,5$ & & CCGCAAGGGATGTGTTGGAATCA & Research Biolabs, Singapore \\
$\mathrm{V} \gamma 9$ & ACGGCACTGTCAGAAAGGAATC & Research Biolabs, Singapore \\
$\mathrm{V} \gamma 10$ & & AATCCGCAGCTCGACGCAGCA & Research Biolabs, Singapore \\
$\mathrm{V} \gamma 11$ & & GGCTCAAGATTGCTCvAGGTGG & Research Biolabs, Singapore
\end{tabular}


be at least two times the maximum height of the polyclonal distribution. Peaks which fell below this ratio were regarded as indeterminate, or oligoclonal if multiple peaks were seen. A normal or bellshaped distribution and nonreproducible patterns were interpreted as negative (polyclonal).

\section{Results}

There were 42 cases, of which 35 (83\%) were Chinese, five were Malays, one was Indian, and one was a Eurasian (Table 2). This approximately reflects the distribution of the ethnic groups in Singapore. ${ }^{28}$ The mean age was 44 years. There were $34(81 \%)$ males and eight $(19 \%)$ females.
Of the 42 cases, 35 cases had localized disease while seven had disease involvement in two or more sites. The upper aerodigestive tract was the most common site of presentation, being involved in 31 out of 42 cases $(74 \%)$. The other sites of manifestation included the skin, gastrointestinal tract, testis, soft tissue, brain, liver, spleen and bone marrow. In all, 32 out of 39 patients (82\%) presented with stage I and II disease, and the remaining $18 \%$ presented with advanced disease (Table 3). A total of 21 patients $(60 \%)$ with NK/TCL with follow-up data had low IPI of $0-1$ while the other $14(40 \%)$ had IPI score of 2 or more. Of 30 patients, $20(68.5 \%)$ were treated with chemotherapy, one patient $(2.9 \%)$ with radiotherapy, and six $(20 \%)$ with both chemotherapy and radiotherapy. Of 38 patients

Table 2 Clinical, immunophenotypic and genetic findings of NK/TCL

\begin{tabular}{|c|c|c|c|c|c|c|c|c|c|c|c|c|c|c|}
\hline $\begin{array}{l}\text { Case } \\
\text { no. }\end{array}$ & Age & Sex & Race & Site & $C D 3$ & $C D 4$ & $C D 8$ & CD56 & TIA-1 & p53 & $p 21$ & EBER & $\begin{array}{l}\text { T-cell } \\
\text { clonality }\end{array}$ & $\begin{array}{l}\text { Surviva } \\
\text { (weeks) }\end{array}$ \\
\hline 1 & 66 & $\mathrm{M}$ & $\mathrm{Ch}$ & Nasal cavity & + & - & - & + & + & + & + & + & G & 38 \\
\hline 2 & 74 & $\mathrm{M}$ & $\mathrm{Ch}$ & Nasal cavity & + & - & - & + & + & + & + & + & $\mathrm{R}$ & 8 \\
\hline 3 & 41 & $\mathrm{M}$ & $\mathrm{Ch}$ & Paranasal sinus & + & - & - & + & + & + & - & + & G & 5 \\
\hline 4 & 37 & $\mathrm{M}$ & $\mathrm{Ch}$ & $\begin{array}{l}\text { Hypopharynx, tonsil, liver, } \\
\text { spleen, bone marrow }\end{array}$ & + & - & + & + & + & + & - & + & G & 3 \\
\hline 5 & 61 & $\mathrm{M}$ & $\mathrm{Ch}$ & Nasal cavity, skin, bone marrow & + & _- & + & + & + & + & + & + & G & 464 \\
\hline 6 & 36 & $\mathrm{M}$ & $\mathrm{Ch}$ & Nasal cavity & + & + & - & + & + & - & - & + & $\mathrm{G}$ & 227 \\
\hline 7 & 53 & $\mathrm{M}$ & $\mathrm{Ch}$ & Pharynx & + & - & + & + & + & - & + & + & $\mathrm{G}$ & 10 \\
\hline 8 & 38 & $\mathrm{~F}$ & $\mathrm{Ch}$ & Nasal cavity, tonsil & + & - & + & + & + & + & + & + & ND & 9 \\
\hline 9 & 46 & $\mathrm{M}$ & $\mathrm{Ch}$ & Nasal cavity, GIT, liver & + & - & + & + & + & - & + & + & $\mathrm{G}^{*}$ & 61 \\
\hline 10 & 20 & $\mathrm{M}$ & $\mathrm{Ch}$ & Paranasal sinus & + & ND & ND & - & + & _- & - & + & $\mathrm{G}^{*}$ & 137 \\
\hline 11 & 49 & $\mathrm{M}$ & $\mathrm{Ch}$ & Paranasal sinus & + & + & - & + & + & - & - & + & $\mathrm{G}^{*}$ & 120 \\
\hline 12 & 44 & $\mathrm{M}$ & $\mathrm{Ch}$ & Nasal cavity & + & - & - & + & + & + & + & + & $\mathrm{G}^{*}$ & 19 \\
\hline 13 & 31 & $\mathrm{~F}$ & $\mathrm{Ch}$ & Nasal cavity, paranasal sinus & + & - & - & + & + & - & + & + & $\mathrm{G}^{*}$ & 179 \\
\hline 14 & 49 & $\mathrm{~F}$ & $\mathrm{Ch}$ & Nasal cavity, nasopharynx & + & - & - & - & + & - & - & + & $\mathrm{G}^{*}$ & 23 \\
\hline 15 & 62 & $\mathrm{M}$ & $\mathrm{Ch}$ & Nasal cavity, nasopharynx & + & - & - & + & + & _- & + & + & $\mathrm{G}^{*}$ & 4 \\
\hline 16 & 53 & $\mathrm{M}$ & $\mathrm{Ch}$ & Nasal cavity, CSF & + & - & - & + & + & - & + & + & $\mathrm{G}^{*}$ & 11 \\
\hline 17 & 30 & $\mathrm{M}$ & $\mathrm{Ch}$ & Tonsil, & + & - & + & + & + & - & + & + & $\mathrm{G}^{*}$ & 1 \\
\hline 18 & 55 & $\mathrm{M}$ & $\mathrm{Ch}$ & Oropharynx, nasopharynx & + & - & - & + & + & - & - & + & $\mathrm{G}^{*}$ & 144 \\
\hline 19 & 52 & $\mathrm{~F}$ & $\mathrm{Ch}$ & Nasal cavity & + & - & - & + & + & - & - & + & $\mathrm{G}^{*}$ & 257 \\
\hline 20 & 37 & $\mathrm{M}$ & $\mathrm{Ma}$ & Nasal cavity & + & - & - & + & + & + & + & + & $\mathrm{G}^{*}$ & 284 \\
\hline 21 & 44 & $\mathrm{M}$ & Ma & Paranasal sinus & + & - & - & + & + & - & - & - & $\mathrm{G}^{*}$ & 21 \\
\hline 22 & 54 & $\mathrm{M}$ & $\mathrm{Ch}$ & Nasal cavity & + & - & - & - & + & - & - & + & $\mathrm{G}^{*}$ & 45 \\
\hline 23 & 33 & $\mathrm{M}$ & Ma & Nasal cavity, paranasal sinus & + & - & - & + & + & - & + & + & $\mathrm{G}^{*}$ & 66 \\
\hline 24 & 22 & $\mathrm{~F}$ & $\mathrm{Ch}$ & Nasal cavity, paranasal sinus & + & - & - & - & + & - & - & + & $\mathrm{G}^{*}$ & $<1$ \\
\hline 25 & 66 & $\mathrm{M}$ & Eurasian & Nasal cavity, paranasal sinus & + & - & - & + & + & + & - & + & $\mathrm{R}$ & 8 \\
\hline 26 & 67 & M & $\mathrm{Ch}$ & Paranasal sinus & + & + & + & + & + & - & + & + & $\mathrm{R}$ & 26 \\
\hline 27 & 42 & $\mathrm{M}$ & $\mathrm{Ch}$ & Nasopharynx, oropharynx & + & - & - & - & + & _- & - & + & $\mathrm{R}$ & 71 \\
\hline 28 & 70 & $\mathrm{M}$ & $\mathrm{Ch}$ & Nasal cavity & + & - & + & + & + & + & + & + & $\mathrm{R}$ & 40 \\
\hline 29 & 42 & $\mathrm{M}$ & In & Paranasal sinus & + & + & - & + & + & + & + & + & $\mathrm{R}$ & 23 \\
\hline 30 & 26 & $\mathrm{M}$ & $\mathrm{Ch}$ & Paranasal sinus & + & - & - & + & + & - & - & + & $\mathrm{R}$ & 416 \\
\hline 31 & 42 & $\mathrm{M}$ & $\mathrm{Ch}$ & Nasal cavity & + & - & - & - & + & + & + & + & $\mathrm{R}$ & $<1$ \\
\hline 32 & 48 & M & $\mathrm{Ma}$ & GIT & + & - & - & - & + & - & - & + & $\mathrm{G}^{*}$ & 18 \\
\hline 33 & 53 & $\mathrm{~F}$ & $\mathrm{Ch}$ & GIT & + & - & - & + & + & - & - & + & $\mathrm{G}^{*}$ & 231 \\
\hline 34 & 24 & $\mathrm{M}$ & $\mathrm{Ch}$ & GIT & + & - & - & + & + & + & - & + & $\mathrm{G}^{*}$ & 1 \\
\hline 35 & 63 & $\mathrm{M}$ & $\mathrm{Ch}$ & Skin, liver, spleen, bone marrow & + & - & - & + & + & - & - & + & $\mathrm{G}^{*}$ & 6 \\
\hline 36 & 75 & $\mathrm{M}$ & $\mathrm{Ch}$ & Skin, testis & + & - & + & + & + & + & - & + & $\mathrm{G}^{*}$ & 35 \\
\hline 37 & 80 & $\mathrm{~F}$ & $\mathrm{Ch}$ & Skin & + & - & - & + & + & - & + & + & $\mathrm{G}^{*}$ & 17 \\
\hline 38 & 64 & $\mathrm{~F}$ & $\mathrm{Ch}$ & Skin & + & - & - & - & + & + & - & + & $\mathrm{R}$ & $<1$ \\
\hline 39 & 69 & $\mathrm{M}$ & $\mathrm{Ch}$ & testis, soft tissue & + & - & - & + & + & - & - & + & $\mathrm{G}^{*}$ & 7 \\
\hline 40 & 65 & $\mathrm{M}$ & $\mathrm{Ch}$ & Soft tissue & + & - & - & - & + & + & + & + & $\mathrm{G}^{*}$ & 17 \\
\hline 41 & 61 & M & $\mathrm{Ma}$ & Testis & + & - & - & - & + & + & - & + & $\mathrm{R}$ & 16 \\
\hline 42 & 40 & M & $\mathrm{Ch}$ & Brain & + & - & - & - & + & - & - & + & $\mathrm{R}$ & 27 \\
\hline
\end{tabular}

Ch, chinese; Ma, Malay; In, Indian; M, male; F, female; GIT, gastrointestinal tract; CSF, cerebrospinal fluid; * , pseudospikes; G, germ line; R, rearranged; TIA-1,T-cell intracellular antigen-1; EBER, Epstein-Barr virus encoded RNA; ND, not done. 
Table 3 Summary of clinical data

\begin{tabular}{lrr}
\hline & No. of cases & $\%$ \\
\hline Outcome $(\mathrm{n}=38)$ & 30 & 79 \\
$\quad$ Dead & 8 & 21 \\
Alive & & \\
Stage $(\mathrm{n}=39)$ & 20 & 51 \\
I & 12 & 31 \\
II & 1 & 3 \\
III & 6 & 15 \\
IV & & \\
& & 60 \\
IPI $(\mathrm{n}=35)$ & 21 & 40 \\
Low & 14 & \\
High & & 37 \\
Treatment $(\mathrm{n}=30)$ & 20 & 20 \\
C & 1 & 10 \\
RT & 6 & \\
C+RT & 3 & \\
None & & \\
\hline
\end{tabular}

IPI, international prognostic index; R, radiotherapy; C, chemotherapy; $\mathrm{R}+\mathrm{C}$, radiotherapy and chemotherapy.

with follow-up information, 30 had died (Table 3).

The histologic features of the NK/TCL were similar irrespective of the site of involvement. Of the 42 cases, necrosis was observed in 26 (62\%) and angiocentricity (Figure 1a) in 22 cases $(52 \%)$. Apoptosis was another common feature encountered in almost all the cases. The lymphoid infiltrate was frequently polymorphous with accompanying eosinophils, plasma cells and histiocytes. The neoplastic lymphoid cells demonstrated a broad spectrum of appearances, ranging from small cells (Figure 1b) with irregular serpentine nuclei $(9.5 \%)$, medium-sized cells $(28.5 \%)$ (Figure 1c), to large pleomorphic cells with vesicular nuclei and prominent nucleoli $(43 \%)$ (Figure 1d). A total of $19 \%$ of the cases displayed a mixture of small to large cells. Clear cytoplasm was noted in seven cases $(17 \%)$. In one case (case 35), a 63-year-old man with neutropenia and thrombocytopenia, was diagnosed as an aggressive NK-cell leukemia/lymphoma. He presented with skin tumors and hepatosplenomegaly, and his bone marrow aspirate showed atypical large granular lymphocytes in $20 \%$ of the granulocytes.

All the patients showed positive staining for CCD3 and TIA- 1 . The majority of the cases $(71 \%)$ were negative for both CD4 and CD8. Of all the cases, 20\% were $\mathrm{CD} 4-/ \mathrm{CD} 8+, 7 \%$ were CD4 + /CD8-, and $2 \%$ were CD4 +/CD8 + (Table 2). Immunoreactivity for CD2 was observed in $73 \%$ of the cases, CD56 expression was present in $74 \%$, and granzyme B in $88 \%$ of the tumors. Except for one nasal tumor (case 21), all cases expressed EBER (97.6\% of all cases) (Figure 1e).

\section{T-Cell Clonality with Gel and Capillary Electrophoresis}

Monoclonal T-cell receptor- $\gamma$ gene rearrangement was detected in 11 out of 41 cases (27\%) of NK/TCL analyzed, while the remaining $30(73 \%)$ had germline T-cell receptor- $\gamma$ gene (Figs 2 and 3). Of the 11 cases which showed clonal T-cell receptor- $\gamma$ gene rearrangement, eight cases were in the upper aerodigestive tract, one in the skin, and one each in the testis and brain (Table 2). Tumors with clonal T-cell receptor- $\gamma$ gene rearrangement revealed similar histologic features to those which were polyclonal for T-cell receptor- $\gamma$ gene. Comparing the results of T-cell clonality with CD56 expression, we found that six out of the 30 cases $(20 \%)$ of true NKcell tumors with germline T-cell receptor- $\gamma$ gene were CD56 negative, while five out of 11 cases (45\%) of the T-cell-derived tumors lacked CD56 expression. As defined earlier in this study, the only case which was negative for EBER had germline T-cell receptor- $\gamma$ gene. In 24 out of 30 cases interpreted as polyclonal for T-cell receptor- $\gamma$ gene, nonreproducible pseudospikes were noted in the capillary electrophoresis.

\section{p53 and p21 Expression}

Immunohistochemical evaluation of p53 and p21 were performed to obtain indirect information about the functional status of the p53 gene. ${ }^{29}$.The p53 +1 p21 + pattern (Figure 4a and b) was present in 10 out of 42 cases of NK/TCL, while the p53+/p21pattern was observed in seven cases and the p53-/p21 + pattern was seen in nine cases (Table 2 ). The $\mathrm{p} 53-/ \mathrm{p} 21-$ pattern was the predominant pattern and was present in 16 out of $42(38 \%)$ cases. No significant association between p53 overexpression $(>10 \%$ of tumor cells with positive staining) and size of tumor cells was detected. There was also no statistically significant association between p53 overexpression with advanced stage of disease, and decreased survival.

\section{Survival}

The mean survival time was 30 months (Figure 5a). Patients with NK/TCL with low IPI had significantly better survival rate than patients with IPI of 2 or more (median survival 8.7 vs 2.7 months, $P=0.015$ ) (Figure 5b). Patients younger than 60 years and female patients appeared to have longer survival time (Figure $5 \mathrm{c}$ and d), although the differences were not statistically significant $(P=0.052$ and $P=0.173$, respectively). There was no significant decrease in survival rates with advanced stage of disease, p53 overexpression and large cell size. No survival advantage was detected between tumor sites, treatment modalities, EBER expression, and cell lineage. 

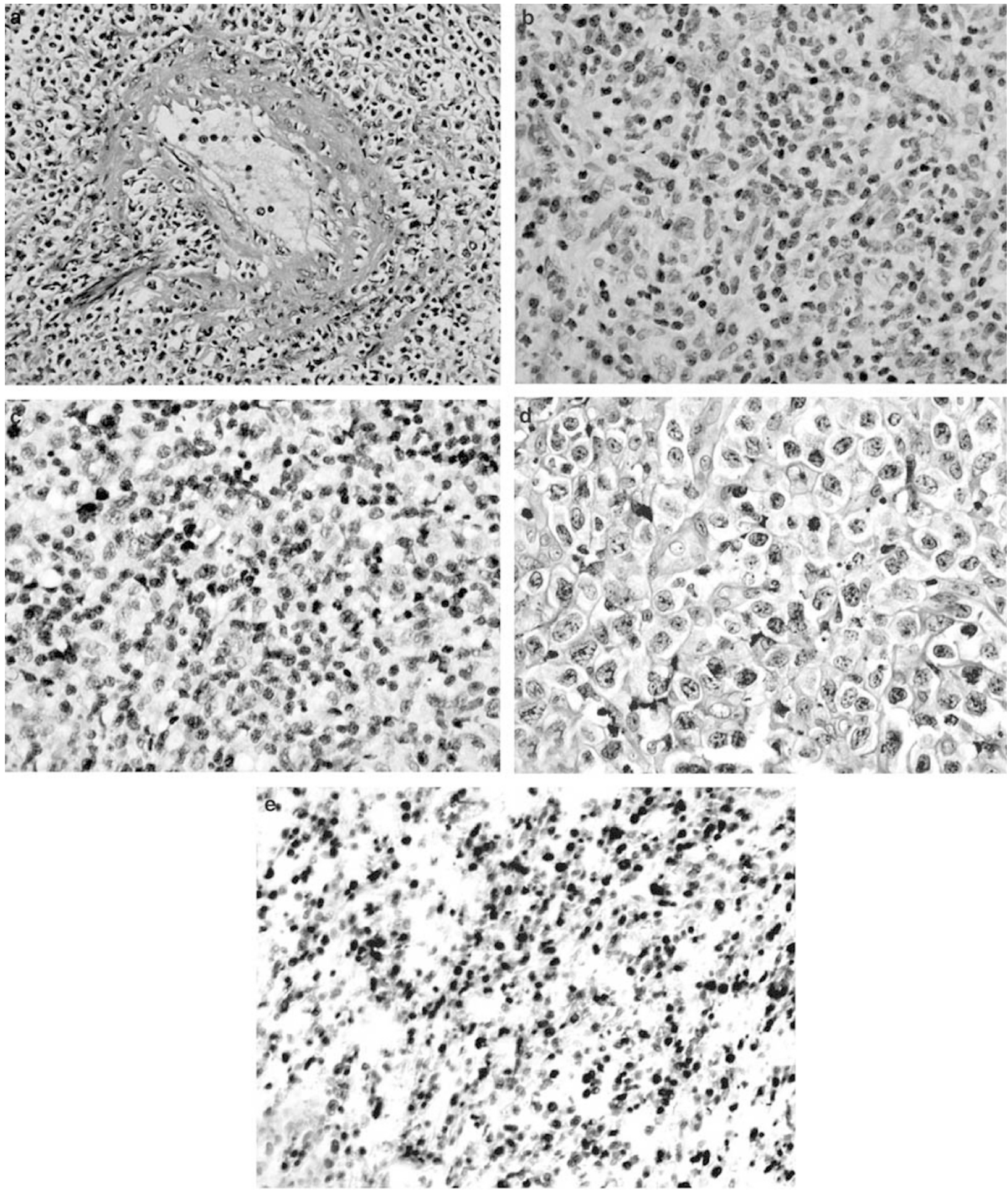

Figure 1 Histologic features of nasal-type NK/TCL. (a) Tumor cells infiltrating and destroying a blood vessel. (b) Tumor with predominant small cells showing slightly irregular nuclei. An accompanying polymorphous inflammatory infiltrate is present. (c) Tumor with small and medium-sized cells. (d) Tumor consisting of mainly large lymphoid cells with vesicular nuclei and distinct nucleoli. (e) Expression of EBER in situ hybridization in the tumor cell nuclei.

\section{Discussion}

Extranodal NK/TCL includes several distinct entities, of which nasal-type NK/TCL, enteropathy-type
TCL, and subcutaneous panniculitic-like TCL represent the prototypic examples. ${ }^{2}$ The classification of extranodal NK/TCL is based on a constellation of clinical, morphologic, immunophenotypic and 


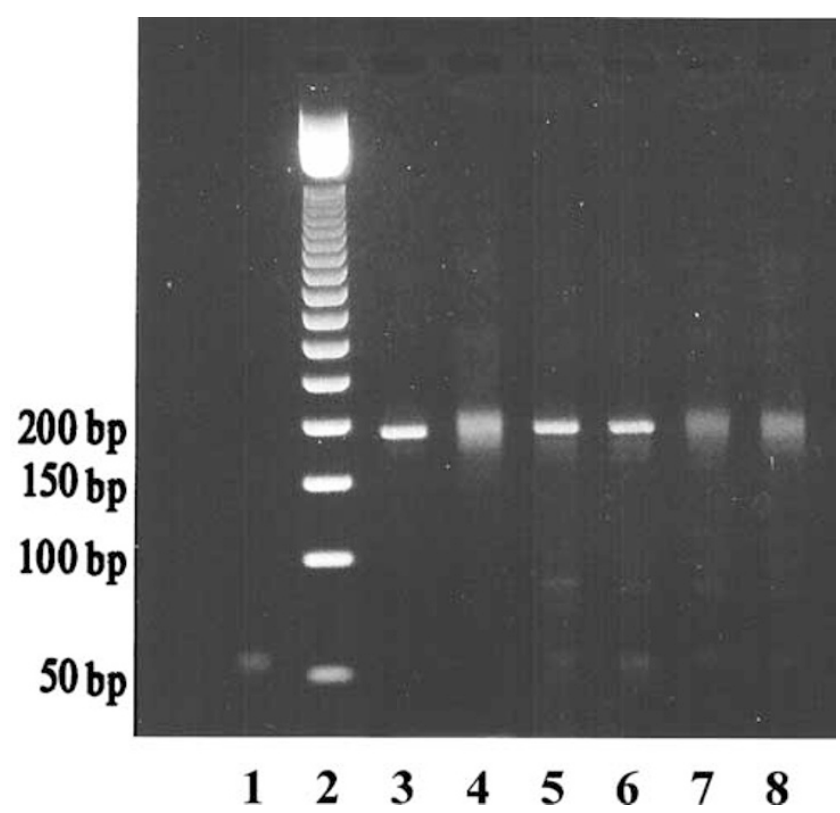

Figure 2 PCR for T-cell receptor- $\gamma$ gene using agarose gel electrophoresis. Lane 1: Negative control. Lane 2: 50-base pair molecular weight marker. Lane 3: monoclonal (positive) control. Lane 4: polyclonal (negative) control. Lanes 5 and 6: Monoclonal T-cell receptor- $\gamma$ gene rearrangement in reproducible duplicate. Lanes 7 and 8: Polyclonal T-cell receptor- $\gamma$ gene rearrangement (smear pattern) in reproducible duplicate.

genetic features. ${ }^{2}$ These tumors almost invariably show a cytotoxic T- or NK-cell phenotype and the prevalence of Epstein-Barr virus relates to the geographical origin of the patient and anatomic sites of involvement, being more frequently positive in the nasal than intestinal or subcutaneous tumors. ${ }^{6}$ Disease definition is thus, heavily dependent upon clinical findings, rather than the cell lineage. ${ }^{2}$ These tumors have in common, many clinicopathologic features and similar tumors may show variation in immunophenotype and genotype. As such, many of them cannot be neatly classified according to the recognized categories.

The nasal-type NK/TCL in this study showed clinicopathologic findings similar to those of previous studies in Asian and Western countries. ${ }^{8,15,19,20}$ In all, $82 \%$ of our cases presented with stage I and II disease, while $18 \%$ had stage III and IV disease at presentation. The sites of initial involvement included upper aerodigestive tract, skin, gastrointestinal tract, liver, spleen, bone marrow, testis, lung, brain and soft tissue. The cases had similar histologic features, which encompassed angiocentricity, necrosis, ulceration, apoptosis, and a polymorphous inflammatory infiltrate. All cases expressed at least one T-cell marker and one or both markers for cytotoxic granule protein. CD56 expression was noted in $74 \%$, and the majority was negative for CD4 and CD8. NK/TCL is strongly associated with Epstein-Barr virus in all geographic areas studied. The strength of association is reported
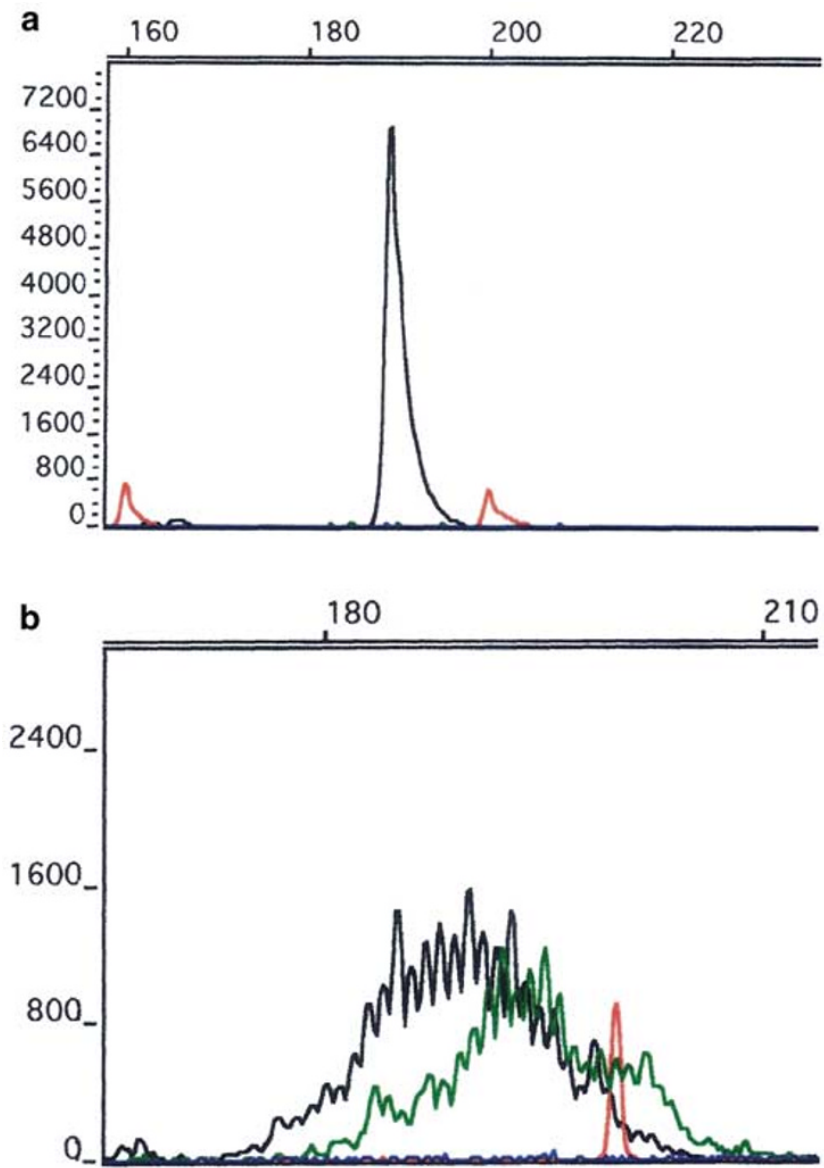

Figure 3 Electropherogram of PCR for T-cell receptor- $\gamma$ gene rearrangement using capillary electrophoresis. The three dyes used for joining region primer labeling were FAM (J $\gamma$ P-blue), Vic ( $\gamma \gamma \mathrm{P} 1 / \mathrm{J} \gamma \mathrm{P} 2$-green), and NED (J $\gamma 1 / \mathrm{J} \gamma 2$-black) (a) Monoclonal peak with height ratio more than 2. (b) Polyclonal T-cell receptor- $\gamma$ gene rearrangement demonstrated by the bell-shaped distribution pattern.

to vary from 100 to $75 \%$ in the Asian populations. ${ }^{16}$ Some studies in the Caucasian population also detected a strong but not invariable association with Epstein-Barr virus. ${ }^{16,30}$ In extranasal sites, the association with the virus is more variable, ${ }^{30}$ and Tsang et $a l^{31}$ reported EBER expression in $62.5 \%$ of non-nasal CD56-positive TCLs. In this study, 96.7\% of the cases of NK/TCL in the upper aerodigestive tract and all the tumors in the extranasal sites were positive for EBER. In the majority of these cases, Epstein-Barr virus signals were detected in the nuclei of many tumor cells. A few cases, however, showed more focal positivity for the viral RNA. Patients with low IPI showed significantly better survival rates than patients with IPI of two or more. Younger female patients also appeared to have a longer survival time, although this was not statistically significant. Survival rate did not correlate with anatomic sites, EBER expression, cell size and cell lineage. In contrast to the study by Ko et $a l,{ }^{8}$ we did not find any association between stage and survival time. 
1104

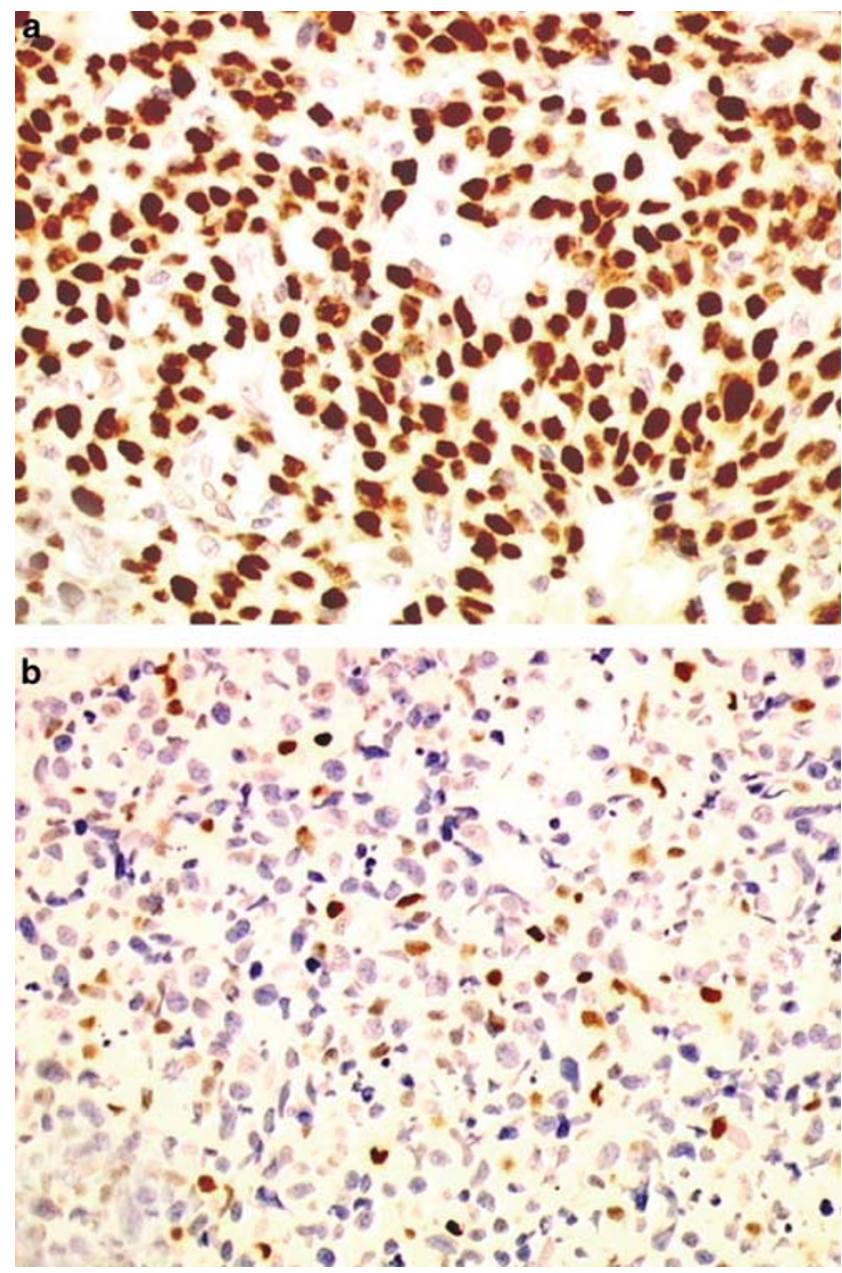

Figure 4 Immunohistochemical evaluation of p53 and p21. Tumor cells showed positive staining for p53 (a) and p21 (b).

Most cases of NK/TCL have an NK-cell phenotype as indicated by the absence of surface CD3, presence of CD56 and CD3 $\varepsilon$ in the cytoplasm, and lack of

T-cell receptor gene rearrangement. However, a minority of these tumors with indistinguishable clinical, histologic and immunophenotypic features may express a T-cell phenotype and show monoclonal T-cell receptor gene rearrangement. ${ }^{1,2,6,19} \mathrm{~A}$ recent study described the presence of restricted killer immunoglobulin-like receptor repertoire and monoclonal T-cell receptor gene rearrangement in six out of 15 cases of sinonasal lymphomas, suggesting a mixed NK/T-cell differentiation in a subset of these tumors. ${ }^{32}$

The cell lineage of NK/TCL has been evaluated in several studies using molecular genetic techniques. In the nasal-type NK/TCL, clonal T-cell receptor gene rearrangement detected by either Southern blot hybridization or PCR, has been reported in three of 13 cases, ${ }^{33}$ one of 11 cases, ${ }^{34}$ none of 21 cases, ${ }^{35}$ none of six cases ${ }^{36}$ and three of 31 cases. $^{8}$ Taken together, seven of 82 cases $(8.5 \%)$ were reported as having a T-cell lineage. Except for that of Ko et al which employed a seminested PCR method with reported sensitivity of $78-100 \%$, most of the other studies utilized simple PCR technique with sensitivity of about $70 \% .{ }^{8}$ Two studies using multiplex PCR method with improved sensitivity, have reported clonal T-cell receptor- $\gamma$ gene rearrangement in one of nine $\operatorname{cases}^{37}$ and one of 14 cases $^{20}$ of NK/TCL. Notably, we identified clonal T-cell receptor- $\gamma$ gene rearrangement in a significantly higher proportion $(27 \%)$ of our cases, compared to the earlier studies mentioned..$^{8,33-36}$ We adopted a highly sensitive multiplex PCR method ${ }^{28}$ and analyzed the amplified PCR products by capillary electrophoresis using an automated DNA fragment analyzer, which is not only of higher sensitivity than conventional gel electrophoresis, but also allows semiquantitative analysis and highly precise determination of PCR product sizes within 1 base pair. Other advantages include rapid turnaround time and more efficient use of technologist resources. ${ }^{12}$ Capillary electrophoresis has been described as a more objective and sensitive technique than gel electrophoresis in establishing clonality in peripheral TCL, ${ }^{12,27,38}$ but this method has yet to be evaluated in the analysis of NK/TCL. In this study, we found capillary electrophoresis to be particularly useful for detecting monoclonal peaks within polyclonal backgrounds, identifying small clonal populations, and distinguishing pseudospikes from true monoclonal peaks. This highly sensitive detection technique is superior to conventional gel electrophoresis and probably accounts for the higher proportion of true T-cellderived tumors in this study. Interestingly, pseudospikes were noted in 24 out of 30 (80\%) cases which lacked clonal T-cell receptor- $\gamma$ gene rearrangement. Lee et $a l^{39}$ described pseudospikes as a common finding when they used capillary electrophoresis and examined the spectrum of normal patterns for T-cell receptor- $\gamma$ gene in a variety of T-cell rich, histologically benign tissue types, and compared this with the patterns in TCLs. An important distinguishing characteristic of the pseudoclonal pattern is the absence of reproducibility in duplicate reactions. The exact clinical significance of these 'pseudospikes' or 'oligoclonal peaks' in NK/TCL remains unascertained and it is unclear whether they are a result of tumor heterogeneity, random amplification of a low number of $\mathrm{T}$ cells in the samples, or related to the frequently abundant background polyclonal T-cell targets present in NK/TCL, which effectively compete with the monoclonal population during amplification. ${ }^{40}$

Mutation of the p53 gene is frequently implicated in the pathogenesis of many human cancers. The wild-type protein is normally present in cells at undetectable levels because of its very short halflife. The presence of missense mutations in this gene leads to an enhanced stability of the protein, allowing its detection by immunohistochemistry. ${ }^{41}$ However, some mutations of p53 gene do not result in its accumulation, while functional inactivation of 

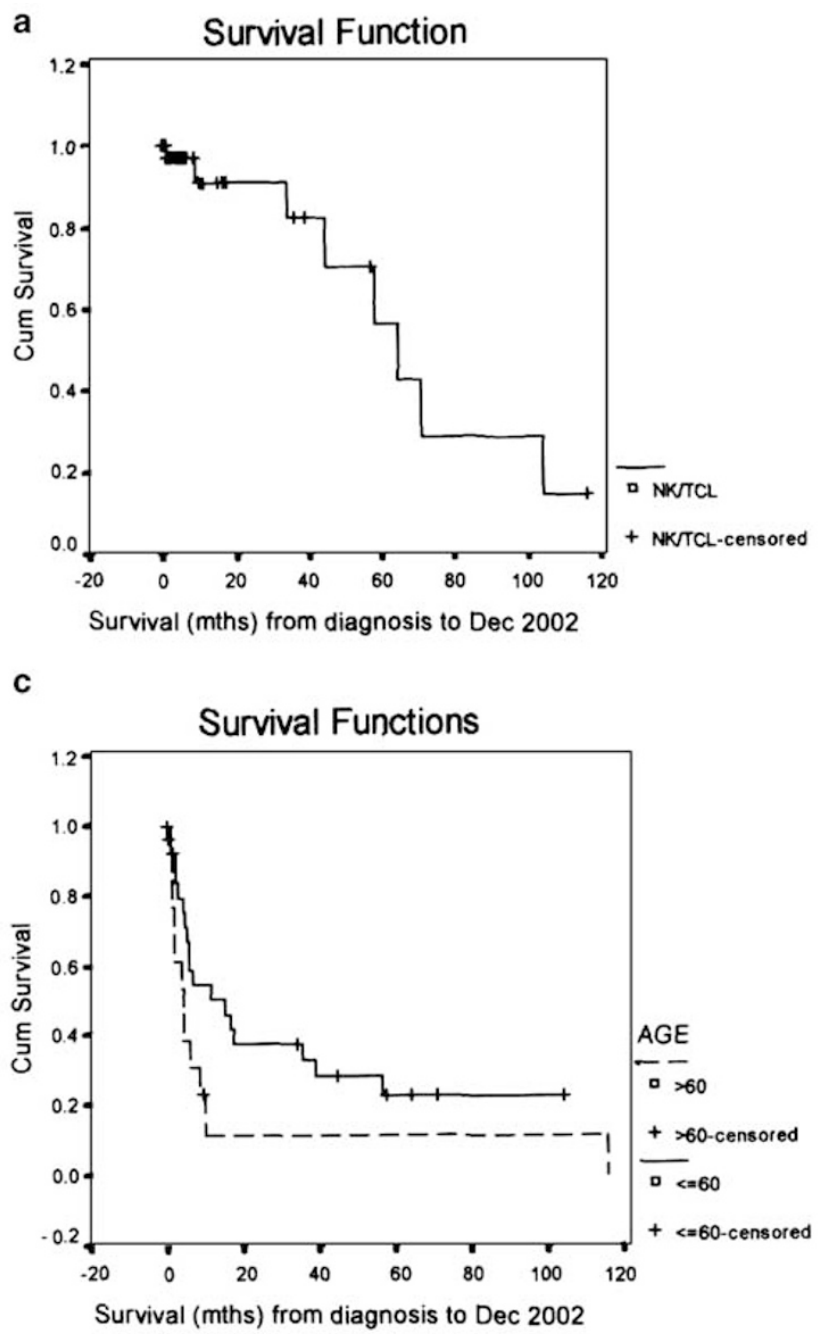

b

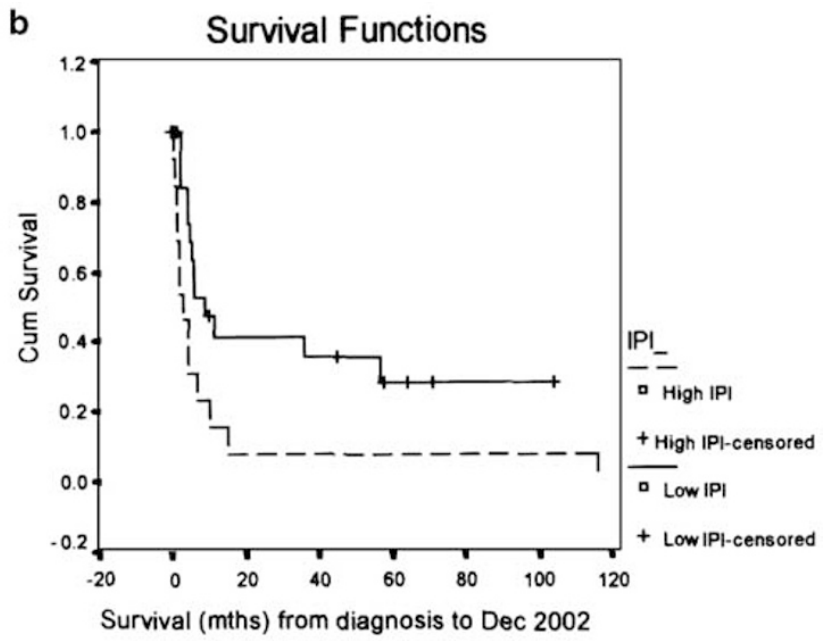

d

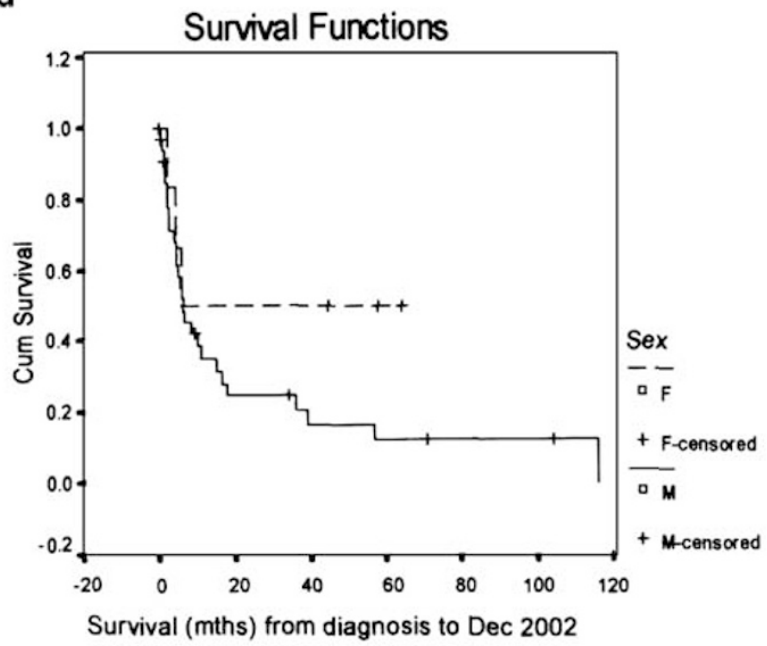

Figure 5 Kaplan-Meier survival curves. (a) Survival curve of patients with NK/TCL. (b) Survival curves of patients with low International Prognostic Index (0-1) and high International Prognostic Index of two or more, $P=0.015$. (c) Survival curve of patients above and below 60 years old, $P=0.052$, and (d) Survival curve of male and female patients, $P=0.173$.

the gene resulting in detectable amounts of p53 protein, can occur in the absence of mutations. ${ }^{29} \mathrm{~A}$ few studies have reported a high percentage of p53 overexpression in nasal NK/TCL ${ }^{29,13}$ and QuintanillaMartinez et $\mathrm{al}^{14}$ found an association between p53 mutations with large cell morphology and advanced disease. We studied the functional status of the overexpressed p53 protein in NK/TCL by correlating the expression of p53 gene with its downstream target protein, p21, which is a cyclin-dependent kinase inhibitor shown to be a good surrogate marker for the functional status of p53 gene. ${ }^{42}$ When there is overexpression of wild-type functional p53, p21 protein is usually detectable, whereas the absence of p21 correlates with the presence of missense p53 mutations. In all, 10 out of 42 cases $(24 \%)$ in our study showed the p53+/p21 + staining pattern, indicating accumulation of wild-type functional p53 protein. In seven cases $(17 \%)$, the $\mathrm{p} 53+/ \mathrm{p} 21-$ pattern was detected, which may indicate the presence of a p53 gene mutation. However, functional inactivation of p53, resulting in detectable amounts of inactivated protein, can occur via mechanisms other than mutations. Some of these mechanisms proposed include binding of p53 to viral proteins, such as Epstein-Barr virus, and deregulation of the mdm2induced p53 degradation. ${ }^{29}$ The p53-/p21 + pattern was seen in nine of 42 cases $(21 \%)$. This pattern of staining seemed to suggest that p21 is upregulated independent of p53 gene status. The p53-/ p21- pattern was the predominant pattern of staining seen in $38 \%$ of the tumors, suggesting the absence of abnormality of the p53 pathway in these tumors. However, other than missense mutations, some mutations in the p53 gene do not result in the accumulation of the protein. ${ }^{43}$ Overall, p53 overexpression was detected in only $40 \%(17 / 42)$ of the tumors, indicating that other genetic aberrations, in addition to alterations in the p53 pathway, may be operative in the pathogenesis of these neoplasms. No 
significant difference in survival rate was detected in patients with p53 overexpression. There was also no association between p53 overexpression with large cell morphology, and advanced stage of disease.

In summary, NK-cell malignancies are aggressive neoplastic disorders with distinctive clinicopathologic profile, genotypic features, and geographical distribution. In this present study, NK/TCL with a low IPI showed significantly better survival rates than patients with IPI of two or more. Unlike previous studies on NK/TCL, a significantly higher percentage $(27 \%)$ of the lymphomas in our study showed clonal T-cell receptor- $\gamma$ gene rearrangement by PCR gel and capillary electrophoresis. Even though there was no significant association between survival and cell lineage, it remains unclear if this Tcell subset forms a distinct entity, or if a true mixed NK/T-cell differentiation exists. ${ }^{32}$ Aberration of the p53 pathway was present in $40 \%$ of the cases but no significant difference in survival rate was detected in patients with p53 overexpression and there was also no association between p53 overexpression with large cell morphology, and advanced stage of disease. The etiology of this tumor remains to be elucidated, although a consistent association with Epstein-Barr virus infection suggests that this virus may be involved in the pathogenesis. Further studies are required to delineate molecular and biologic markers to facilitate the diagnosis, and to develop more effective treatment strategies.

\section{Acknowledgements}

We wish to thank Professor Wing C (John) Chan from the Department of Pathology, University of Nebraska Medical Center, for his invaluable assistance in the interpretation of our capillary electrophoresis results, and Dr Zhao Yi, from the Department of Clinical Research, Singapore General Hospital, for assisting with the capillary electrophoresis analysis. We also thank Jennifer Ho from the Department of Pathology, Singapore General Hospital, for performing the EBER in situ hybridization, Dr Wang Shi for assistance in compilation of data, and Department of Hematology, Singapore General Hospital.

\section{Duality of interest}

None.

\section{References}

1 Jaffe ES, Chan JKC, Su I-J, et al. Report of the workshop on nasal and related extranodal angiocentric T/natural killer cell lymphomas. Definitions, differential diagnosis, and epidemiology. Am J Surg Pathol 1996;20:103-111.

2 Kluin PM, Feller A, Gaulard P, et al. Peripheral T/NKcell lymphoma: a report of the IXth workshop of the
European Association for Haematopathology. Histopathology 2001;38:250-270.

3 Siu LLP, Chan JKC, Kwong YL. Natural killer cell malignancies: clinicopathologic and molecular features. Histo Histopathol 2002;17:539-554.

4 Jaffe ES, Ralfkiaer E. Mature T-cell and NK-cell neoplasms. In: Jaffe ES, Harris NL, Stein H, Vardiman (eds). Pathology and Genetics of Tumours of Haematopoietic and Lymphoid Tissues. IARC Press: LyonFrance, 2001, pp. 191-235.

5 Jaffe ES. Lymphoid lesions of the head and neck: a model of lymphocyte homing and lymphomagenesis. Mod Pathol 2002;15:255-263.

6 Jaffe ES, Krenacs L, Kumar S, et al. Extranodal peripheral T-cell and NK-cell neoplasms. Am J Clin Pathol 1999;111:S46-S55.

7 Kanavaros P, De Bruin PC, Briere J, et al. Epstein-Barr virus (EBV) in extranodal T-cell non-Hodgkin's lymphomas (T-NHL). Identification of nasal T-NHL as a distinct clinicopathological entity associated with EBV. Leuk Lymphoma 1995;18:27-34.

8 Ko YH, Ree HJ, Kim WS, et al. Clinicopathologic and genotypic study of extranodal nasal-type natural killer/ T-cell lymphoma and natural killer precursor lymphoma among Koreans. Cancer 2000;89:2106-2116.

9 Yoon TY, Lee HT, Chang SH. Nasal-type T/natural killer cell angiocentric lymphoma, Epstein-Barr virusassociated, and showing clonal T-cell receptor $\gamma$ gene rearrangement. Br J Dermatol 1999;140:505-508.

10 Jaffe ES. Classification of natural killer (NK) cell and NK-like T-cell malignancies. Blood 1996;87:1207-1210.

11 Kinney MC. The role of morphologic features, phenotype, genotype, and anatomic site in defining extranodal T-cell or NK-cell neoplasms. Am J Clin Pathol 1999;111:S104-S118.

12 Sprouse JT, Werling R, Hanke D, et al. T-cell clonality determination using polymerase chain reaction (PCR) amplification of the T-cell receptor gamma-chain gene and capillary electrophoresis of fluorescently labeled PCR products. Am J Clin Pathol 2000;113:838-850.

13 Quintanilla-Martinez L, Franklin JL, Guerrero I, et al. Histological and immunophenotypic profile of nasal NK/T cell lymphomas from Peru: high prevalence of p53 overexpression. Hum Pathol 1999;30:849-855.

14 Quintanilla-Martinez L, Kremer M, Keller G, et al. p53 mutations in nasal Natural Killer/T-cell lymphoma from Mexico. Association with large cell morphology and advanced disease. Am J Pathol 2001;159:2095-2105.

15 Chan JKC, Sin VC, Wong KF, et al. Nonnasal lymphoma expressing the natural killer cell marker CD56: a clinicopathologic study of 49 cases of an uncommon aggressive neoplasm. Blood 1997;89: 4501-4513.

16 Cheung MMC, Chan JKC, Lau WH, et al. Primary nonHodgkin's lymphoma of the nose and nasopharynx: clinical features, tumor immunophenotype, and treatment outcome in 113 patients. J Clin Oncol 1998;16:70-77.

17 Nakamura S, Koshikawa T, Koike K, et al. Clinicopathologic study of CD56 (NCAM)-positive angiocentric lymphoma occurring in sites other than the upper and lower respiratory tract. Am J Surg Pathol 1995;19:284-296.

18 Ratech H, Burke JS, Blayney DW, et al. A clinicopathologic study of malignant lymphomas of the nose, paranasal sinuses, and hard palate, including cases of lethal midline granuloma. Cancer 1989;64: 2525-2531. 
19 Gaal K, Sun NCJ, Hernandez AM, et al. Sinonasal NK/ T-cell lymphomas in the United States. Am J Surg Pathol 2000;24:1511-1517.

20 Van Gorp J, De Bruin PC, Sie-Go DMDS, et al. Nasal Tcell lymphoma: a clinicopathological and immunophenotypic analysis of 13 cases. Histopathology 1995;27:139-148.

21 Mraz-Gernhard S, Natkunam Y, Hoppe RT, et al. Natural killer/natural killer like T-cell lymphoma, CD56+, presenting in the skin: an increasingly recognized entity with an aggressive course. J Clin Oncol 2001;19:2179-2188.

22 Rodriguez J, Romaguera JE, Manning J, et al. Nasaltype T/NK lymphomas: a clinicopathologic study of 13 cases. Leukemia Lymphoma 2000;39:139-144.

23 Schmid MH, Bird P, Dummer R, et al. Tumor burden index as a prognostic tool for cutaneous T-cell lymphoma. Arch Dermatol 1999;135:1204-1208.

24 el-Deiry WS, Tokino T, Waldman T, et al. Topological control of $\mathrm{p} 21^{\mathrm{WAF} 1 / \mathrm{CIP} 1}$ expression in normal and neoplastic tissues. Cancer Res 1995;55:2910-2919.

25 Mateo MS, Saez AI, Sanchez-Beato M, et al. Expression of p21 $1^{\mathrm{WAF} 1 / \mathrm{CIP} 1}$ in fetal and adult tissues: simultaneous analysis with Ki67 and p53. J Clin Pathol 1997;50: 645-653.

26 Villuendas R, Pezzella F, Gatter K, et al. p21 $1^{\mathrm{WAF} / \mathrm{CIP} 1}$ and MDM2 expression in non-Hodgkin's lymphoma and their relationship to p53 status: A p53+, MDM2-, p21immunophenotype associated with missense p53 mutations. J Pathol 1997;181:51-61.

27 Greiner TC, Rubocki RJ. Effectiveness of capillary electrophoresis using fluorescent-labeled primers in detecting T-cell receptor $\gamma$ gene rearrangements. J Mol Diagn 2002;4:137-143.

28 Chia KS, Seow A, Lee HP, et al. Cancer Incidence in Singapore 1993-1997. Singapore Cancer Registry: Singapore, 2000.

29 Petit B, Leroy K, Kanavaros P, et al. Expression of p53 protein in T- and natural killer-cell lymphomas is associated with some clinicopathologic entities but rarely related to p53 mutations. Hum Pathol 2001;32: 196-204.

30 Vidal RW, Devaney K, Ferlito A, et al. Sinonasal malignant lymphomas: a distinct clinicopathological category. Ann Otol Rhinol Laryngol 1999;108:411-419.

31 Tsang WYW, Chan JKC, Yip TTC, et al. In situ localization of Epstein-Barr virus encoded RNA in nonnasal/nasopharyngeal CD56-positive and CD56-negative T-cell lymphomas. Hum Pathol 1994;25:758-765.

32 Lin CW, Yang JY, Chuang YC, et al. Presence of restricted killer immunoglobulin-like receptor repertoire and monoclonal T-cell receptor $\gamma$ rearrangement as evidence of mixed NK/T-cell differentiation in a subset of sinonasal lymphomas. Lab Invest 2003; 83:55-64.

33 Chiang AKS, Chan ACL, Srivastava G, et al. Nasal T/ Natural killer (NK)-cell lymphomas are derived from Epstein-Barr virus-infected cytotoxic lymphocytes of both NK- and T-cell lineage. Int J Cancer 1997;73: 332-338.

34 Takeshita M, Yoshida K, Suzumiya J, et al. Cases of cutaneous and nasal CD56 (NCAM)-positive lymphoma in Japan have differences in immunohistology, genotype, and etiology. Hum Pathol 1999; 30:1024-1034.

35 Ohsawa M, Nakatsuka S, Kanno H, et al. Immunophenotypic and genotypic characterization of nasal lymphoma with polymorphic reticulosis morphology. Int J Cancer 1999;81:865-870.

36 Ho FC, Srivastava G, Loke SL, et al. Presence of Epstein-Barr virus DNA in nasal lymphomas of B and 'T' cell type. Hematol Oncol 1990;8:271-281.

37 Emile J-F, Boulland M-L, Haioun C, et al. CD5 ${ }^{-} \mathrm{CD}^{+} 6^{+}$ T-cell receptor silent peripheral T-cell lymphomas are natural killer cell lymphomas. Blood 1996;87: 1466-1473.

38 Oda RP, Wick MJ, Rueckert LM, et al. Evaluation of capillary electrophoresis in polymer solutions with laser-induced fluorescence detection for the automated detection of T-cell gene rearrangements in lymphoproliferative disorders. Electrophoresis 1996;17: 1491-1498.

39 Lee SC, Berg KD, Racke FK, et al. Pseudo-spikes are common in histologically benign lymphoid tissues. J Mol Diagn 2000;2:145-152.

40 Elenitoba-Johnson KSJ, Bohling SD, Mitchell RS, et al. PCR analysis of the immunoglobulin heavy chain gene in polyclonal processes can yield pseudoclonal bands as an artifact of low B cell number. J Mol Diagn 2000;2:92-96.

41 Legros Y, Meyer A, Ory K, et al. Mutations in p53 produce a common conformational effect that can be detected with a panel of monoclonal antibodies directed toward the central part of the p53 protein. Oncogene 1994;9:3689-3694.

42 Chilosi M, Doglioni C, Magalini A, et al. p21/WAF1 cyclin-kinase inhibitor expression in non-Hodgkin's lymphomas: a potential marker of p53 tumor-suppressor gene function. Blood 1996;88:4012-4020.

43 Koduru PRK, Raju K, Vadmal V, et al. Correlation between mutation in p53, p53 expression, cytogenetics, histologic type, and survival in patients with B-cell non-Hodgkin's lymphoma. Blood 1997;90: 4078-4091. 